migraine and epilepsy. "Deep in the brainstem .... is the origin of the migrainous process, slow tonic changes of excitation and inhibition; but the detection of these changes and the demonstration of their nature and cause, have completely eluded us ..." (p. 207). As he freely acknowledges, the author has revaluated older theories of the origin of migraine, as expounded particularly by Liveing and by Hughlings Jackson; but in the light of his own extensive clinical experience, and interpretation of the literature. The style is characterized by many quotations, from Aretaeus to Wittgenstein.

At times he is unjustifiably dogmatic and he tends to do less than justice to viewpoints with which he doesn't agree --for example, he underrates the importance of current work on the biochemical mechanisms, in which the most practical prospects for rational therapy probably lie. His discussion of psychoanalytic aspects is unnecessarily complex and indeed is out of date.

This is not a book with which to begin a study of migraine and it is not a satisfactory source book of scientific information on the subject.

Rita HENRYK-GutT

\section{Hit and Miss}

Molecular Radiation Biology: The Action of Ionizing Radiation on Elementary Biological Objects. By Hermann Dertinger and Horst Jung. Translated by R. P. O. Hüber and P. A. Gresham. Pp. $\mathrm{x}+237$. (Longman: London; Springer-Verlag: New York and Berlin, March 1971.) £3.00.

THERE are at any given time a number of fashionable words and phrases, the judicious use of which may attract attention to a piece of scientific writing. A number of authors have, for example, learned that the inclusion of "DNA" in the title of a paper guarantees an extra two hundred reprint requests from perusers of Current Contents. Another example of a fashionable phrase, I suspect, is "molecular biology", which may explain its inclusion in the title of this book. Molecular biology, if it means anything, means the explanation of biological processes and organization in terms of molecular function and structure. If one expected Molecular Radiation Biology to deal very largely with the effect on biological processes and organization of molecules whose structure and function had been altered by radiation, one would be disappointed. The book deals rather with the hypotheses and facts about the absorption of energy and the production of damaged molecules; chemistry and physics rather than biology.

A more honest title would have been
"Radiation Biophysics" or "Physicochemical Aspects of Radiation Biology". Judged in that context, the book has very much to commend it. There are excellent chapters on the primary processes of energy absorption, hit theory and target theory, including most of the important recent developments. They provide good evidence that target theory is alive and well and can still provide a unifying basis for radiation biology. Much of the progress in this field has come from the study of treatments which modify the sensitivity of biological molecules, such as oxygen, temperature, water and chemical protective agents. Although at first sight the existence of sensitivity modifiers might seem to be inconsistent with target theory, this is not so and the authors have done well to include them convincingly within the general framework of target theory. It is surprising, however, that no mention is made of the interesting developments made in the field of chemical sensitizing agents during the last decade.

There have been several attempts in recent years to characterize hypothetical radiation lesions in DNA on the basis of, for example, their reparability, susceptibility to oxygen, and differential induction with radiations of different linear energy transfer. Dertinger and Jung have made a useful synthesis of these various attempts, but it is unfortunate that they have used the terminology of one group of workers but with new meanings including those applied by other workers to a different terminology. Although self-consistent within the book, confusion could arise if readers were to go to the original literature, although failure to make proper attribution makes this somewhat difficult.

There is a substantial chapter on the effect of irradiating ribonuclease, a topic on which one of the authors has worked, and four chapters on nucleic acids and viruses. Only one of the fourteen chapters attempts to deal with the response of living things (in this case bacteria) to altered molecules of DNA, and it is one best ignored. The authors may be excused for much of it being now out of date, but not for the oversimplifications and errors it contains, revealing a superficial knowledige of the biological aspects of their subject.

It is stated that the book originated from teaching material, and as a biophysical introduction to radiation bio$\operatorname{logy}$ it is to be recommended for students rather more strongly than my reservations above might imply. The book's limitations could always be made good in other ways. As an introduction to the subject for postgraduates it is also good, but access to the more biological literature would have to be sought elsewhere.

B. A. BRIDGES

\section{Chain Reactions}

Introduction to the Kinetics of Chemical Chain Reactions. By F. G. R. Gimblett. (European Chemistry Series.) Pp. viii+199. (McGraw-Hill : Maidenhead and New York, 1970.) £2.10.

IT is difficult to see the justification for a book on this subject intended solely for the undergraduate. It will be the exceptional student who reads the whole book, and he will not find it particularly well balanced. For the majority, who would probably only read some sections, this is not a serious criticism.

After an introductory chapter, the author deals with the hydrogen halogen reactions and the treatment is more detailed and up to date than in other elementary texts. This chapter, which could have been an excellent one, is spoiled by some statements that are either wrong or misleading for the undergraduate reader. It is also repetitive in places (this fault recurs throughout the book). The hydrogen fluoride reaction could, with advantage, have been left out.

Gimblett then continues with a discussion of linear chain reactions involving free radicals. It seems to me misguided to introduce the Rice-Herzfeld mechanism by a discussion of the poorly understood pyrolysis of $n$-hexane. The treatment of the ethane decomposition is quite good, though here and elsewhere there is the usual overemphasis on reaction order and the apparent lack of understanding that many of the unimolecular steps which occur in chain reactions do not have integral orders. Some of the suggested chain ending steps cannot be the major ones, and to quote a chain length to four significant figures would be considered a crime even for a second year undergraduate. A short venture into photochemistry suggests the author is not at home in this field.

Branched chain reactions are dealt with in a reasonably satisfactory way, and this is followed by a treatment of liquid phase reactions. This latter chapter lacks unity. Inhibition of chain reactions is an important subject and the author deals with this aspect in some detail. While it has been important historically, the inhibition of hydrocarbon pyrolyses by nitric oxide should not be treated in an elementary text.

A final chapter on experimental techniques for identification of chain carriers and the study of their behaviour is an excellent idea. It is, however, a pity that the balance is not good and once again there are misleading statements. Half the number of techniques dealt with at twice the length would have been far more helpful. SI units are not used, and in many tables the units of the "A" factors are not quoted at all.

H. M. FreY 